\section{Late reaction to ustekinumab infusion}

\author{
Marina Resener Morais, Luana Pizarro \\ Meneghello, Carina Flores de Oliveira, \\ André Vicente Esteves Carvalho
}

Irmandade Santa Casa de Misericórdia de Porto Alegre, Brazil

\begin{abstract}
Psoriasis is a chronic inflammatory disease that directly affects the quality of life. Biologics are prescribed for patients unresponsive to conventional treatments and with severe forms of the disease. Ustekinumab is a fully human monoclonal antibody against the p40 subunit of interleukins 12/23 that is being used with satisfactory responses, achieving an improvement in the baseline Psoriasis Area and Severity Index of approximately $75 \%$ after 12 weeks of treatment. It has few side effects, including grater susceptibility to infections and development of reactions to the drug. Our report discusses a case of a cutaneous reaction to the use of ustekinumab in a 27 year-old male patient after the third dose of the medication. No similar case has been reported in the literature.
\end{abstract}

\section{Introduction}

Psoriasis is a chronic inflammatory skin disease with courses of remission and worsening, which can have great impact on quality of life. Patients with moderate-to-severe psoriasis usually require continuous treatment with higher chances of toxicity. The biologics are used in patients whose condition could not be controlled with conventional treatments, or had to discontinue it due to side effects or toxicity. ${ }^{1,2}$ Ustekinumab is a human monoclonal antibody indicated for the treatment of moderate-to-severe psoriasis. Its mechanism of action is based on the inactivation of interleukins 12 and 23 p40 subunit. Patients treated with this medication are being monitored for a better definition of long-term effectiveness and side effects. ${ }^{2,3}$

This paper describes a case of late onset reactions to ustekinumab infusion.

\section{Case Report}

A 27-year-old man, diagnosed with psoriasis since he was 15 , had been treated with acitretin, methotrexate, cyclosporine and pho- totherapy. However, since his symptoms became refractory to treatment, ustekinumab has been indicated. Baseline Psoriasis Area and Severity Index (PASI) was 11.2, BSA $>10 \%$, and a DLQI $>10$. He was administered one subcutaneous injection of $45 \mathrm{mg}$ of ustekinumab on week 0 and a subsequent injection of $45 \mathrm{mg}$ after 4 weeks, which led to the complete resolution of the lesions. As public supply of the medication was restrained, the patient only received the first maintenance dose 11 months after the last infusion. A week after reintroduction of ustekinumab, pruritic and erythematous annular eruptions occurred on the patient's trunk and limbs (Figures 1 and 2). Blood test shows eosinophilia. Dexchlorpheniramine was prescribed. The patient returned after two weeks showing complete improvement of lesions.

\section{Discussion and Conclusions}

Psoriasis is the most common immunemediated chronic inflammatory disease affecting approximately $2 \%$ to $3 \%$ of the world's population. ${ }^{1-6}$ Around $80 \%$ of patients present localized plaque psoriasis, while the generalized forms comprise less than $20 \%$. The disease has a major impact on the quality of life and can be compared to diabetes mellitus, rheumatoid arthritis, depression and cancer. Typically, psoriasis patients will usually cycle through therapies and sometimes will require indefinite treatment. ${ }^{1}$

In the psoriasis pathophysiology, IL-12 activates $\mathrm{CD} 4 \mathrm{~T}$ cells and natural killer cells that induce the production of type 1 cytokines (TNF interferon alpha), while IL-23 stimulates the proliferation and increases the half-life of $\mathrm{T}$ cells, which produce IL-17. The IL-2 and IL-23 are secreted after the activation of antigenpresenting cells and both present $\mathrm{p} 40$ sub-unit in their molecules. ${ }^{5}$

Ustekinumab is a fully human monoclonal antibody that binds to the p40 subunit of the interleukins 12 and 23. Three randomized controlled trials have demonstrated that both 45 $\mathrm{mg}$ and $90 \mathrm{mg}$ doses showed a high efficacy in the treatment of psoriasis with $67 \%$ to $72 \%$ of patients achieving a PASI response of 75 at week 12 . Ustekinumab presents few sideeffects. $^{7-9}$

In the PHOENIX 1 study, the most common adverse reactions were upper respiratory tract infection, nasopharyngitis, headache and arthralgia, affecting $0.8 \%$ of patients who were taking $45 \mathrm{mg}$, and $1.6 \%$ of those who used 90 mg. ${ }^{8}$ In PHOENIX 2, rates of serious infections were low in all treatment groups. The occurrence of injection site reactions was $1 \%$ of 5632 injections of ustekinumab and $0,4 \%$ of 14,919 placebo injections, which could in part
Correspondence: Marina Resener Morais, Irmandade Santa Casa de Misericórdia de Porto Alegre, Rua Prof. Annes Dias 285 - 1 andar, Porto Alegre, RS 90020-090, Brazil.

Tel./Fax: +55.513.2148008

E-mail: mariresener@hotmail.com

Key words: psoriasis, ustekinumab, late adverse skin reactions.

Contributions: the authors contributed equally.

Conflict of interests: the authors declare no potential conflict of interests.

Received for publication: 8 July 2013 . Accepted for publication: 22 July 2013.

This work is licensed under a Creative Commons Attribution NonCommercial 3.0 License (CC BY NC 3.0).

(C) Copyright M.R. Morais et al., 2013

Licensee PAGEPress, Italy

Dermatology Reports 2013; 5:e2

doi:10.4081/dr.2013.e2

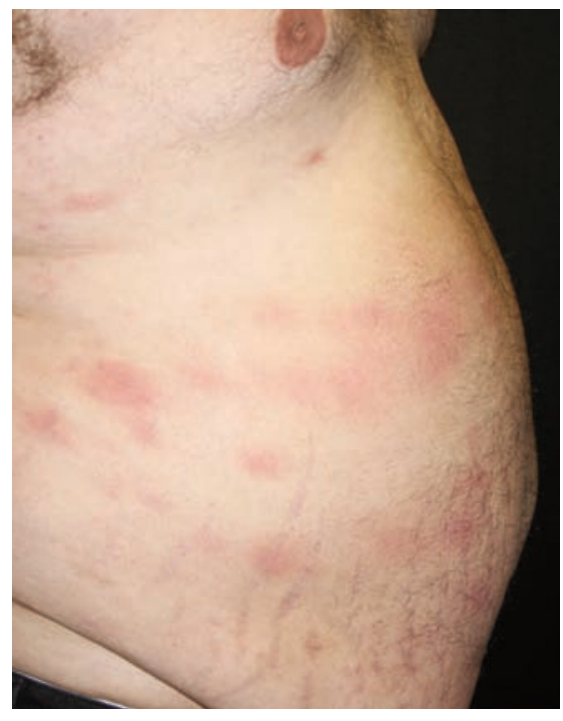

Figure 1. Macular eruption after the treatment.

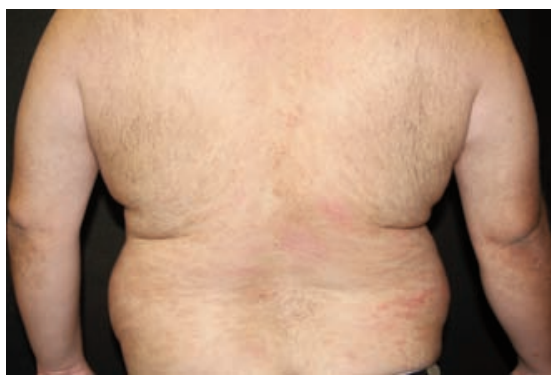

Figure 2. Exanthematous eruptions after the treatment. 
be related to the infrequent dosing interval. ${ }^{9}$ The acute reactions occurs during the infusion or in the first 24 hours. The majority can be classified as mild or moderate reactions and only few are severe. Late reactions occur between 24 hours and 14 days after an infusion, in most cases symptoms include arthralgia, myalgia, influenza-like symptoms, headache and rash or urticaria. ${ }^{10}$ In patients with Crohn's disease treated with infliximab $61 \%$ patients had detectable antibodies against infliximab after the fifth infusion. They found a strong relation between the concentration of antibodies against the infliximab and the occurrence of an infusion reaction. The study showed a cumulative incidence of infusion reactions of $27 \%$, no one occurred during the first infusion and the incidence increased during the subsequent infusions. ${ }^{11}$

In PHOENIX 1 and 2 the immunogenicity rates were low, with approximately $5 \%$ patients developing anti-ustekinumab antibodies and these were not associated with injection site reactions. ${ }^{8,9}$ Our patient have presented late reaction to ustekinumab when the treatment was discontinued and antibodies were probably produced. No report on this type of reaction during the use of ustekinumab was found in the literature. More studies are necessary to understand the relation between antibodies against ustekinumab and infusion reactions.

\section{References}

1. Smith CH, Anstey AV, Barker JN, et al. British Association of Dermatologists' guidelines for biologic interventions for psoriasis 2009. Br J Dermatol 2009;161: 987-1019.

2. Lebwohl M, Leonardi C, Griffiths CE, et al. Long-term safety experience of ustekinumab in patients with moderate-tosevere psoriasis (part I of II): results from analyses of general safety parameters from pooled phase 2 and 3 clinical trials. J Am Acad Dermatol 2012;66:731-41.

3. Gordon KB, Papp KA, Langley RG, et al. Long-term safety experience of ustekinumab in patients with moderate to severe psoriasis (part II of II): results from analyses of infections and malignancy from pooled phase II and III clinical trials. J Am Acad Dermatol 2012;66:742-51.

4. Scherl EJ, Kumar S, Warren RU. Review of the safety and efficacy of ustekinumab. Therap Adv Gastroenterol 2010;3:321-8.

5. Famenini S, Wu JJ. The safety of ustekinumab in psoriasis. J Drugs Dermatol 2012; 11:907-10.

6. Yeilding N, Szapary P, Brodmerkel C, et al. Development of the IL-12/23 antagonist ustekinumab in psoriasis: past, present, and future perspectives. Ann NY Acad Sci 2011;1222:30-9.

7. Yeilding N, Szapary P, Brodmerkel C, et al. Development of the IL-12/23 antagonist ustekinumab in psoriasis: past, present, and future perspectives--an update. Ann NY Acad Sci 2012;1263:1-12.

8. Leonardi CL, Kimball AB, Papp KA, et al. Efficacy and safety of ustekinumab, a human interleukin-12/23 monoclonal antibody, in patients with psoriasis: 76-week results from a randomised, double-blind, placebo-controlled trial (PHOENIX 1). Lancet 2008;371:1665-74.

9. Papp KA, Langley RG, Lebwohl M, et al. Efficacy and safety of ustekinumab, a human interleukin-12/23 monoclonal antibody, in patients with psoriasis: 52 -week results from a randomised, double-blind, placebo-controlled trial (PHOENIX 2). Lancet 2008;371:1675-84.

10. Lecluse LLA, Piskin G, Mekkes JR, et al. Review and expert opinion on prevention and treatment of infliximab-related infusion reactions. Br J Dermatol 2008;159: 527-36.

11. Baert F, Noman M, Vermeire S, et al. Influence of immunogenicity on the longterm efficacy of infliximab in Crohn's disease. N Engl J Med 2003;348:601-8. 